\title{
Performance Habits: A Framework Proposal
}

\author{
Sylvain Laborde ${ }^{1,2 *}$, Daniela Kauschke ${ }^{1,3}$, Thomas J. Hosang ${ }^{4}$, Florian Javelle ${ }^{5}$ and \\ Emma Mosley ${ }^{6}$
}

${ }^{1}$ Department of Performance Psychology, German Sport University Cologne, Cologne, Germany, ${ }^{2}$ Normandie Université, Caen, France, ${ }^{3}$ Universität Mannheim, Mannheim, Germany, ${ }^{4}$ Helmut Schmidt University, Hamburg, Germany, ${ }^{5}$ Department of Sport Medicine, German Sport University Cologne, Cologne, Germany, ${ }^{6}$ Southampton Solent University, Southampton, United Kingdom

Keywords: optimization, automatic processes, habits, performance, human

"We are what we repeatedly do. Excellence, then, is not an act but a habit." Aristotle

\section{INTRODUCTION}

Improving one's performance is a persistent desire for many individuals. Performance is often used as an umbrella term to describe the behavior and activities of individuals or larger entities, such as organizations, and could ultimately be linked to evolutionary success (Buss, 2019). Specifically, we define performance as how effectively an action is executed and how successful behavior is to achieve a goal [based on (McGarry, 2013; Raab et al., 2015)].

One common tip to improve performance is developing habits. Various definitions of habits

OPEN ACCESS

Edited by:

Gary Edward McPherson,

The University of Melbourne, Australia

Reviewed by:

Adina Mornell,

University of Music and Performing

Arts Munich, Germany

*Correspondence.

Sylvain Laborde

s.laborde@dshs-koeln.de

Specialty section:

This article was submitted to

Performance Science,

a section of the journal

Frontiers in Psychology

Received: 08 April 2020

Accepted: 01 July 2020

Published: 19 August 2020

Citation:

Laborde S, Kauschke D, Hosang TJ,

Javelle F and Mosley E (2020)

Performance Habits: A Framework

Proposal. Front. Psychol. 11:1815.

doi: 10.3389/fpsyg.2020.01815 coexist in the literature, and in this paper we consider habits as processes "by which a stimulus generates an impulse to act as a result of a learned stimulus-response association" [(Gardner, 2015), p. 277]. Habits are driven by automatic processes in that they do not require conscious and intentional processing of related information (Graybiel, 2008; Lally and Gardner, 2013). Habits should be distinguished from routines, which can be viewed as organized activities with purpose, direction, sequence, outcomes, and repetition, but which are not necessarily based on a learned stimulus-response association (Clark, 2000; Charmaz, 2002; Gardner, 2015). Rituals are often used as a synonym for routines; however routines are seen as being rather mostly instrumental to reach a goal, while rituals encompass a symbolic meaning in a specific group context (Fiese et al., 2002). Habitual behavior can be distinguished in terms of habitual instigation - habitually "deciding" to do something — and habitual execution—habitually "doing" something (Gardner et al., 2016, 2020). Regarding habit formation, Lally and Gardner (2013) identified four basic stages: First, a decision must be made to take action. Second, the decision to act must be translated into action. Third, the behavior must be repeated, and finally, the new action must be repeated in a way that leads to automaticity.

The notion that habits can lead to performance optimization is widespread. In fact, a search for "performance habits" returns more than 500 million hits on Google (with mostly business websites, such as Forbes, "10 Daily Habits of the Most Productive Leaders"1). More than 3,000 books are available on Amazon, with some bestsellers such as "High Performance Habits: How Extraordinary People Become That Way" (Burchard, 2017) or "Tools of Titans: the Tactics, Routines, and Habits of Billionaires, Icons, and World-Class Performers" (Ferriss, 2017). The majority of non-scientific "expert" recommendations on habits to improve performance originate from those who have reached an elite level in a specific domain (e.g., business, sports, music, politics, etc.) or a certain

${ }^{1}$ Retrieved on June 15, 2020: https://www.forbes.com/sites/deeppatel/2017/07/14/10-daily-habits-of-the-most-productiveleaders/\#49599b407e9c. 
social status. Subsequently they then present those habits as key influential factors for their success (Burchard, 2017; Ferriss, 2017). However, beyond those anecdotal reports and popular interest, to date very few scientific researchers investigated the effectiveness of habits to improve one's performance. So far, the main themes in habit research in human focuses on the formation of health habits (Lally and Gardner, 2013; Gardner, 2015), which is of course of utmost individual and societal importance. Habit research in the field of human performance however is sparse-with some exceptions regarding academic, cognitive, and athletic performance (Cotrena et al., 2016; Dubuc et al., 2019; Longo et al., 2019; Fiorella, 2020; Kristo et al., 2020)— and we aim in this opinion piece to outline a range of dimensions which could benefit from the conceptualization of habits for optimizing performance.

\section{PERFORMANCE HABITS}

We refer to performance habits as habits targeting performance optimization, considering performance as defined above. The theoretical characteristics of habits make them very relevant for performance (Gardner, 2015; Wood, 2017). Indeed paying attention to the numerous factors influencing performance can be quite effortful and cognitively demanding (Raab et al., 2015). Habits, reflecting actions relying on automatic functioning, free up resources for further top-down processing (Graybiel, 2008; Lally and Gardner, 2013) and reduce motivational impairments (Stojanovic et al., 2020). At this point, we should distinguish between habits and the automatic processes driving skill automaticity observed in expert performance, given in this case that the automatic processes are not necessarily the result of a learned stimulus-response association but rather the result of an extensive learning/training phase that automatized skills via a modification in brain activation patterns (Baker and Young, 2014; Yang, 2015). Nonetheless, habits can provide a basis to optimize learning/training in facilitating its instigation and execution (Gardner et al., 2016, 2020), ultimately facilitating skill automatization. In a nutshell, habits can be seen as a tool to help in transferring human behavior driven by conscious processes to human behavior driven by unconscious processes, therefore optimizing resources and performance. Altogether these characteristics make habits an important mechanism through which people can self-regulate and achieve long-term goals (Wood, 2017). Consequently, people willing to achieve performance goals would benefit from integrating performance habits to their preparation in order to optimize it.

In the following discussion, we introduce a list of dimensions related to activities that have been linked to performance improvement and that could also form into performance habits. To establish this list of dimensions representing the basis of the performance habits framework, general principles for mapping reviews were followed (Miake-Lye et al., 2016). Mapping reviews are particularly useful when there is a large diversity of research as a first step to a systematic review and to identify gaps within an area (Cooper, 2016; Perryman,
2016). The database search ${ }^{2}$ was directed to identify metaanalyses and reviews concerning factors influencing human performance, with the aim to derive higher-order dimensions of strategies improving performance that can be turned into habits.

Eight main dimensions emerged from the visual map of the mapping review. First, we find the classical three dimensions identified by neuroscience to underpin performance (Briguglio et al., 2020): eat (i.e., dietary behaviors), move (i.e., exercise), and sleep. Furthermore, we outline five additional dimensions: psychological well-being, as well as strategies to foster learning, productivity, executive function, and creativity. Those eight dimensions are summarized in Figure 1.

\section{Performance Habit Dimensions Dietary Behavior}

Dietary behaviors have a high impact on performance, from academic performance at school to athletes' performance (Burke et al., 2004; Rampersaud et al., 2005). Dietary behavior habits can be related to overall diet, such as the Mediterranean (Soltani et al., 2019), vegetarian (Craddock et al., 2019; Viguiliouk et al., 2019), vegan (Lopez et al., 2019), or gluten-free (Taetzsch et al., 2018) diet. Dietary behavior habits may also be related to supplementation (Van De Walle and Vukovich, 2018; Clifford et al., 2019; Wilson-Barnes et al., 2020) or to having no meal at all, for example, skipping breakfast (Rampersaud et al., 2005), or with intermittent fasting (Aird et al., 2018; Cho et al., 2019).

\section{Exercise}

Regular exercise sustains performance in many domains and across the lifespan (Heyn et al., 2004; Smith et al., 2010; Chang et al., 2012; Álvarez-Bueno et al., 2020). It is now widely acknowledged that exercise benefits from the conceptualization of habits (Hagger, 2019, 2020; Gardner et al., 2020; Phillips, 2020). Regarding performance, the type of exercise (e.g., aerobic, resistance, high-intensity interval training, stretching) should be considered according to the performance outputs expected (Wen et al., 2019; Lee and Stone, 2020; Martland et al., 2020; Wilke et al., 2020).

\section{Sleep}

Sleep is essential for performance, given that partial or chronic sleep deprivation may affect performance in many domains (Pilcher and Huffcutt, 1996; Dewald et al., 2010; Lee et al., 2020). The usefulness of habits for sleep interventions has been showcased by Rebar et al. (2020). Sleep-based interventions have been shown to be effective in triggering positive sleep habits

\footnotetext{
${ }^{2}$ The search was completed on January 13, 2020, with the Web of Science, all databases included, for the past 10 years (period 2010-2020). The following keywords were entered: "meta-analysis" or "review" in the "Title" field and "performance" in the "All Fields" field. All document types (full papers, proceedings papers, meeting abstract, etc.) in English language were considered. All Web of Science categories were included, and 34,654 unique results were retrieved. The results were exported to the reference software Zotero. From the titles and abstracts screening, SL and DK extracted higher-order themes matching the intended scope of the framework (i.e., strategies to improve performance that can be turned into habits) and represented them on a visual map. The visual map was then refined with TH, FJ, and EM until consensus was reached.
} 


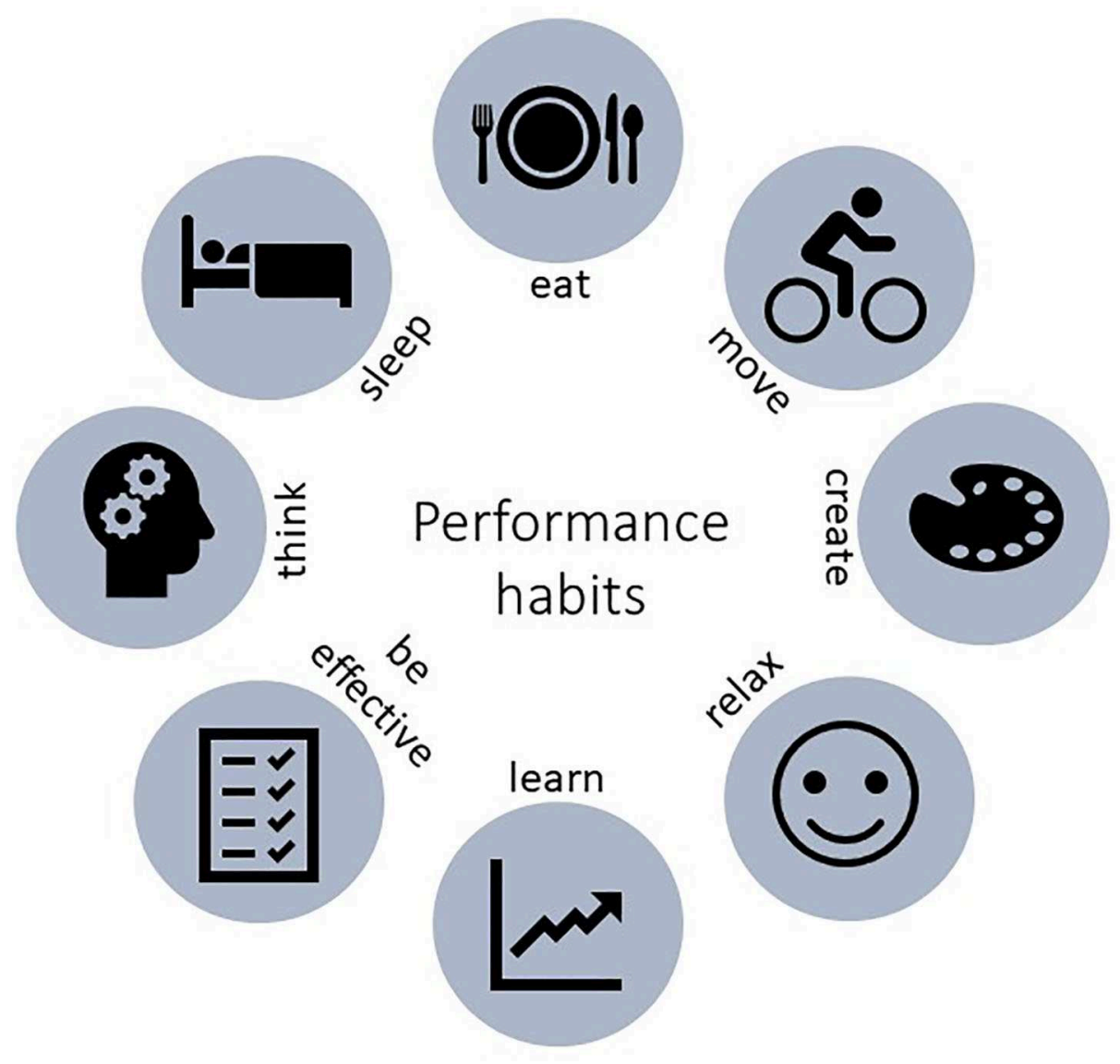

FIGURE 1 | The eight performance habit dimensions are summarized into action verbs: eat (dietary behavior), move (exercise), sleep (sleep), relax (psychological well-being), learn (strategies to foster learning), productivity (strategies to foster productivity), think (strategies to foster executive functioning), and create (strategies to foster creativity). We are aware that the action verbs do not reflect accurately the full spectrum of the dimensions considered, however we believe that they are helpful in order to showcase how individuals may take action to transform them into performance habits.

(Dewald et al., 2010; Chung et al., 2017; Bonnar et al., 2018; Friedrich and Schlarb, 2018). Among the sleep habits promoted by sleep-based interventions, we find, for example, bedtime routines involving decreasing smartphone use (Shin et al., 2017), using relaxation methods (Laborde et al., 2019), or writing to-do lists (Scullin et al., 2018).

\section{Psychological Well-Being}

Psychological well-being (Ryff and Singer, 1996; Ryan and Deci, 2001; Boehm and Kubzansky, 2012) has been shown to positively influence academic performance (Amholt et al., 2020), work performance (Parker et al., 2003; Ford et al., 2011), and sport performance (Lundqvist, 2011). Among the interventions that have been used to promote psychological well-being (Bolier et al., 2013; Ryff, 2014), several methods could be turned into habits to improve performance, such as meditation (Tang, 2014; Chan et al., 2019), progressive muscle relaxation and autogenic training (Manzoni et al., 2008), slow-paced breathing (Zaccaro et al., 2018), journaling (Hensley and Munn, 2020), nature exposure (Kaplan and Berman, 2010), or expressing gratitude (Wood et al., 2010).

\section{Strategies to Foster Learning}

Beyond the mere amount of practice/time spent to learn, the characteristics of learning (e.g., new material, new skill) are very likely to impact subsequent performance in many domains like in academia (Dunlosky et al., 2013), work (Salas and Cannon-Bowers, 2001), and sport (Macnamara et al., 2016). If the habits to learn will depend on the specific learning object, some recommendations can be made at a meta-level, such as developing habits regarding (1) learning techniques, for example, massed vs. distributed learning (Cepeda et al., 2006), (2), learning environment (Dunlosky et al., 2013), considering both the physical (e.g., library vs. at home) and the social aspects (e.g., with a teacher, with peers, alone), and finally (3) learning material, such as books, podcasts, videos, Smartphone apps, etc. (Koçak et al., 2016; Delgado et al., 2018).

\section{Strategies to Foster Productivity}

Productivity refers to the optimization of personal workflow and effectiveness (Fosse et al., 2015; Lewis et al., 2019). It is recommended that individuals develop a personal workflow management system (Lackey et al., 2014), with habits underlying 
productivity, such as distraction minimization (Lewis et al., 2019) and time management interventions (Fosse et al., 2015; Lewis et al., 2019). Distraction minimization (Lewis et al., 2019) would involve, for example, developing habits to effectively handle phone calls, emails, or any internet-based/social network distractions. Time optimization (Fosse et al., 2015; Lewis et al., 2019) is achieved through the programming of short breaks, with efficient note reporting and classification techniques (Lewis et al., 2019), and with using speed-reading techniques (Rayner et al., 2016).

\section{Strategies to Foster Executive Functioning}

Regardless of the performance domain considered, performance to reach a goal will rely on executive functioning, the part of cognitive functioning that allows us to perform goal-directed behavior (Diamond, 2013). Cognitive training programs have been developed to target individuals across the lifespan and have been shown to be effective from pre-schoolers (Scionti et al., 2019) to older adults (Lampit et al., 2014). The extent to which executive functions can be trained or the cognitive training modality of performance would transfer to other domains of performance is still debated (Jak et al., 2013; Simons et al., 2016); most of the research show that improvements are related to the cognitive task or domaintrained (Melby-Lervåg and Hulme, 2013; Butler et al., 2018). Therefore, determining the most relevant executive functions for the performance domain would determine the type of habit developed.

\section{Strategies to Foster Creativity}

In some domains, performance would be related to doing something novel, to synthesize and combine in a new way existing information, thus requiring creativity, also referred to as divergent thinking (Dietrich and Kanso, 2010; Raab et al., 2015). Creativity training focuses on the development of cognitive skills and the heuristics involved in skill application and should use realistic exercises appropriate to the domain at hand (Scott et al., 2004; Valgeirsdottir and Onarheim, 2017). Social interactions should be encouraged to allow brainstorming with other people (Al-Samarraie and Hurmuzan, 2018). Finally, the contexts fostering creativity should be clarified, for example, exercising (Frith et al., 2019) or listening to music (Ritter and Ferguson, 2017).

\section{CONCLUSION}

The aim of this opinion paper was to suggest a framework to investigate habits targeting performance optimization, going beyond the existing health-focused habit research. We developed the idea of performance habits which can be split into individual strategies to improve the following dimensions: eat, move, sleep, relax, learn, be effective, think, and create.
Following the purpose of mapping reviews (Cooper, 2016; Miake-Lye et al., 2016; Perryman, 2016), the goal of this opinion paper was not to reach a definitive conclusion about the field of performance habits but rather to showcase this large area. It is hoped that it will establish the ground for future systematic investigation and experimental endeavor. Consequently, the framework presented should not be considered as definitive but as subject to evolution. The dimensions that we suggest here need to be further refined, with the help of quantitative and qualitative research, to understand the extent to which they effectively contribute to performance according to the domain considered. If some have already received attention from habit researchers (e.g., dietary behavior, physical activity, sleep), we argue that the other dimensions would benefit as well from the theoretical consideration of habits. Additionally, research should also consider to which extent the habit-performance relationship can be seen as a "one-size-fits-all" association or should be better individualized (e.g., Sales et al., 2014) and also investigate the influence of potential moderators such as the use of pharmaceuticals (Marcora, 2016) and biological rhythms (Atkinson and Reilly, 1996). Furthermore, the investigation of these eight dimensions raises some methodological concerns. For example, logging habits linked to strategies fostering learning, productivity, executive functions, and creativity may differ from what has been done so far in habit research and potentially require the development of specific instruments. It should also be taken into account that each dimension may interact with the others regarding their influence on performance. Finally, one should consider that striving for performance may also include the reversal of bad habits, which otherwise may eventually lead to addictive/compulsive behavior (Malloy-Diniz et al., 2019).

At the theoretical level, there is a need to investigate whether habits, based on their characteristics (Gardner, 2015; Wood, 2017), do serve performance better than repetitive (but nonhabitual) ways of realizing certain actions. This will help to develop our understanding of the role of habits in helping individuals to successfully achieve their goals, with the ultimate objective of exploring the extent to which habits are linked to evolutionary human success in that they help to offer stability in an everchanging, complex, and modern human environment (Buss, 2019; Furley, 2019).

\section{AUTHOR CONTRIBUTIONS}

SL and DK prepared the first draft. TH, FJ, and EM provided critical comments to significantly improve the manuscript. All authors contributed to the article and approved the submitted version.

\section{FUNDING}

This work was supported by German Sport University (HIFF L-11-10011-197-052000). 


\section{REFERENCES}

Aird, T. P., Davies, R. W., and Carson, B. P. (2018). Effects of fasted vs fed-state exercise on performance and post-exercise metabolism: a systematic review and meta-analysis. Scand. J. Med. Sci. Sports 28, 1476-1493. doi: 10.1111/sms.13054

Al-Samarraie, H., and Hurmuzan, S. (2018). A review of brainstorming techniques in higher education. Think. Skills Creat. 27, 78-91. doi: 10.1016/j.tsc.2017.12.002

Álvarez-Bueno, C., Hillman, C. H., Cavero-Redondo, I., Sánchez-López, M., Pozuelo-Carrascosa, D. P., and Martínez-Vizcaíno, V. (2020). Aerobic fitness and academic achievement: A systematic review and meta-analysis. J. Sports Sci. 38, 582-589. doi: 10.1080/02640414.2020.1720496

Amholt, T. T., Dammeyer, J., Carter, R., and Niclasen, J. (2020). Psychological wellbeing and academic achievement among school-aged children: a systematic review. Child Indic. Res. 66, 351. doi: 10.1007/s12187-020-09725-9

Atkinson, G., and Reilly, T. (1996). Circadian variation in sports performance. Sports Med. 21, 292-312. doi: 10.2165/00007256-199621040-00005

Baker, J., and Young, B. (2014). 20 years later: deliberate practice and the development of expertise in sport. Int. Rev. Sport Exerc. Psychol. 7, 135-157. doi: 10.1080/1750984x.2014.896024

Boehm, J. K., and Kubzansky, L. D. (2012). The heart's content: the association between positive psychological well-being and cardiovascular health. Psychol. Bull. 138, 655-691. doi: 10.1037/A0027448

Bolier, L., Haverman, M., Westerhof, G. J., Riper, H., Smit, F., and Bohlmeijer, E. (2013). Positive psychology interventions: a meta-analysis of randomized controlled studies. BMC Public Health 13:119. doi: 10.1186/1471-2458$13-119$

Bonnar, D., Bartel, K., Kakoschke, N., and Lang, C. (2018). Sleep interventions designed to improve athletic performance and recovery: a systematic review of current approaches. Sports Med. 48, 683-703. doi: 10.1007/s40279-017$0832-\mathrm{x}$

Briguglio, M., Vitale, J. A., Galentino, R., Banfi, G., Zanaboni Dina, C., Bona, A., et al. (2020). Healthy eating, physical activity, and sleep hygiene (HEPAS) as the winning triad for sustaining physical and mental health in patients at risk for or with neuropsychiatric disorders: considerations for clinical practice. Neuropsychiatr. Dis. Treat. 16, 55-70. doi: 10.2147/NDT.S229206

Burchard, B. (2017). High Performance Habits. New York, NY: Hay House.

Burke, L. M., Kiens, B., and Ivy, J. L. (2004). Carbohydrates and fat for training and recovery. J. Sports Sci. 22, 15-30. doi: 10.1080/0264041031000140527

Buss, D. M. (2019). Evolutionary Psychology: The New Science of the Mind. London: Routledge.

Butler, M., McCreedy, E., Nelson, V. A., Desai, P., Ratner, E., Fink, H. A., et al. (2018). Does cognitive training prevent cognitive decline?: a systematic review. Ann. Intern. Med. 168, 63-68. doi: 10.7326/M17-1531

Cepeda, N. J., Pashler, H., Vul, E., Wixted, J. T., and Rohrer, D. (2006). Distributed practice in verbal recall tasks: a review and quantitative synthesis. Psychol. Bull. 132, 354-380. doi: 10.1037/0033-2909.132.3.354

Chan, J. S. Y., Deng, K., Wu, J., and Yan, J. H. (2019). Effects of meditation and mind-body exercises on older adults' cognitive performance: a meta-analysis. Gerontologist 59, e782-e790. doi: 10.1093/geront/gnz022

Chang, Y. K., Labban, J. D., Gapin, J. I., and Etnier, J. L. (2012). The effects of acute exercise on cognitive performance: a meta-analysis. Brain Res. 1453, 87-101. doi: 10.1016/j.brainres.2012.02.068

Charmaz, K. (2002). The self as habit: the reconstruction of self in chronic illness. OTJR Occupat. Participat. Health 22(Suppl. 1), 31S-41S. doi: $10.1177 / 15394492020220$ s105

Cho, Y., Hong, N., Kim, K.-W., Cho, S. J., Lee, M., Lee, Y.-H., et al. (2019). The effectiveness of intermittent fasting to reduce body mass index and glucose metabolism: a systematic review and meta-analysis. J. Clin. Med. Res. 8:1645. doi: $10.3390 / \mathrm{jcm} 8101645$

Chung, K.-F., Chan, M.-S., Lam, Y.-Y., Lai, C. S.-Y., and Yeung, W.-F. (2017). School-based sleep education programs for short sleep duration in adolescents: a systematic review and meta-analysis. J. Sch. Health 87, 401-408. doi: $10.1111 /$ josh. 12509

Clark, F. A. (2000). The concepts of habit and routine: a preliminary theoretical synthesis. Occupat. Ther. J. Res. 20(Suppl. 1), 123S-137S. doi: $10.1177 / 15394492000200 s 114$
Clifford, T., Jeffries, O., Stevenson, E. J., and Davies, K. A. B. (2019). The effects of vitamin $\mathrm{C}$ and $\mathrm{E}$ on exercise-induced physiological adaptations: a systematic review and meta-analysis of randomized controlled trials. Crit. Rev. Food Sci. Nutr. 18, 1-11. doi: 10.1080/10408398.2019.1703642

Cooper, I. D. (2016). What is a "mapping study?". J. Med. Libr. Assoc. 104, 76-78. doi: 10.3163/1536-5050.104.1.013

Cotrena, C., Branco, L. D., Cardoso, C. O., Wong, C. E., and Fonseca, R. P. (2016). The predictive impact of biological and sociocultural factors on executive processing: the role of age, education, and frequency of reading and writing habits. Appl. Neuropsychol. Adult 23, 75-84. doi: 10.1080/23279095.2015.1012760

Craddock, J. C., Neale, E. P., Peoples, G. E., and Probst, Y. C. (2019). Vegetarianbased dietary patterns and their relation with inflammatory and immune biomarkers: a systematic review and meta-analysis. Adv. Nutr. 10, 433-451. doi: 10.1093/advances/nmy103

Delgado, P., Vargas, C., Ackerman, R., and Salmerón, L. (2018). Don't throw away your printed books: a meta-analysis on the effects of reading media on reading comprehension. Educ. Res. Rev. 25, 23-38. doi: 10.1016/j.edurev.2018.09.003

Dewald, J. F., Meijer, A. M., Oort, F. J., Kerkhof, G. A., and Bögels, S. M. (2010). The influence of sleep quality, sleep duration and sleepiness on school performance in children and adolescents: a meta-analytic review. Sleep Med. Rev. 14, 179-189. doi: 10.1016/j.smrv.2009.10.004

Diamond, A. (2013). Executive functions. Ann. Rev. Psychol. 64, 135-168. doi: 10.1146/annurev-psych-113011-143750

Dietrich, A., and Kanso, R. (2010). A review of EEG, ERP, and neuroimaging studies of creativity and insight. Psychol. Bull. 136, 822-848. doi: $10.1037 / \mathrm{a} 0019749$

Dubuc, M. M., Aubertin-Leheudre, M., and Karelis, A. D. (2019). Lifestyle habits predict academic performance in high school students: the adolescent student academic performance longitudinal study (ASAP). Int. J. Environ. Res. Public Health 17:243. doi: 10.3390/ijerph17010243

Dunlosky, J., Rawson, K. A., Marsh, E. J., Nathan, M. J., and Willingham, D. T. (2013). Improving students' learning with effective learning techniques: promising directions from cognitive and educational psychology. Psychol. Sci. Public Interest 14, 4-58. doi: 10.1177/1529100612453266

Ferriss, T. (2017). Tools of Titans: The Tactics, Routines, and Habits of Billionaires, Icons, and World-class Performers. New York, NY: Houghton Mifflin.

Fiese, B. H., Tomcho, T. J., Douglas, M., Josephs, K., Poltrock, S., and Baker, T. (2002). A review of 50 years of research on naturally occurring family routines and rituals: cause for celebration? J. Fam. Psychol. 16, 381-390. doi: 10.1037//0893-3200.16.4.381

Fiorella, L. (2020). The science of habit and its implications for student learning and well-being. Educ. Psychol. Rev. 32, 603-625. doi: 10.1007/s10648-020-09525-1

Ford, M. T., Cerasoli, C. P., Higgins, J. A., and Decesare, A. L. (2011). Relationships between psychological, physical, and behavioural health and work performance: a review and meta-analysis. Work Stress 25, 185-204. doi: 10.1080/02678373.2011.609035

Fosse, T. H., Buch, R., Säfvenbom, R., and Martinussen, M. (2015). The impact of personality and self-efficacy on academic and military performance: The mediating role of self-efficacy. J. Milit. Stud. 6, 47-65. doi: 10.1515/jms-2016-0197

Friedrich, A., and Schlarb, A. A. (2018). Let's talk about sleep: a systematic review of psychological interventions to improve sleep in college students. J. Sleep Res. 27, 4-22. doi: 10.1111/jsr.12568

Frith, E., Ryu, S., Kang, M., and Loprinzi, P. D. (2019). Systematic review of the proposed associations between physical exercise and creative thinking. Eur. J. Psychol. Assess. 15, 858-877. doi: 10.5964/ejop.v15i4.1773

Furley, P. (2019). What modern sports competitions can tell us about human nature. Perspect. Psychol. Sci. 14, 138-155. doi: 10.1177/17456916187 94912

Gardner, B. (2015). A review and analysis of the use of 'habit' in understanding, predicting and influencing health-related behaviour. Health Psychol. Rev. 9, 277-295. doi: 10.1080/17437199.2013.876238

Gardner, B., Phillips, L. A., and Judah, G. (2016). Habitual instigation and habitual execution: definition, measurement, and effects on behaviour frequency. $\mathrm{Br}$. J. Health Psychol. 21, 613-630. doi: 10.1111/bjhp.12189 
Gardner, B., Rebar, A. L., and Lally, P. (2020). 'Habitually deciding' or 'habitually doing'? A response to Hagger (2019). Psychol. Sport Exerc. 47:101539. doi: 10.1016/j.psychsport.2019.05.008

Graybiel, A. M. (2008). Habits, rituals, and the evaluative brain. Annu. Rev. Neurosci. 31, 359-387. doi: 10.1146/annurev.neuro.29.051605.112851

Hagger, M. S. (2019). Habit and physical activity: theoretical advances, practical implications, and agenda for future research. Psychol. Sport Exerc. 42, 118-129. doi: 10.1016/j.psychsport.2018.12.007

Hagger, M. S. (2020). Redefining habits and linking habits with other implicit processes. Psychol. Sport Exerc. 46:101606. doi: 10.1016/j.psychsport.2019.101606

Hensley, L. C., and Munn, K. J. (2020). The power of writing about procrastination: journaling as a tool for change. J. Further Higher Educ. 1-16. doi: 10.1080/0309877x.2019.1702154

Heyn, P., Abreu, B. C., and Ottenbacher, K. J. (2004). The effects of exercise training on elderly persons with cognitive impairment and dementia: a meta-analysis. Arch. Phys. Med. Rehabil. 85, 1694-1704. doi: 10.1016/j.apmr.2004.03.019

Jak, A. J., Seelye, A. M., and Jurick, S. M. (2013). Crosswords to computers: a critical review of popular approaches to cognitive enhancement. Neuropsychol. Rev. 23, 13-26. doi: 10.1007/s11065-013-9226-5

Kaplan, S., and Berman, M. G. (2010). Directed attention as a common resource for executive functioning and self-regulation. Perspect. Psychol. Sci. 5, 43-57. doi: $10.1177 / 1745691609356784$

Koçak, Ö., Yildirim, Ö., Kurşun, E., and Yildirim, G. (2016). Investigating the status of tablet computers and E-books use of open education faculty students. Int. J. Dist. Educ. Technol. 14, 49-63. doi: 10.4018/ijdet.2016040104

Kristo, A. S., Gultekin, B., Oztag, M., and Sikalidis, A. K. (2020). The effect of eating habits' quality on scholastic performance in turkish adolescents. Behav. Sci. 10:31. doi: 10.3390/bs10010031

Laborde, S., Hosang, T., Mosley, E., and Dosseville, F. (2019). Influence of a 30-day slow-paced breathing intervention compared to social media use on subjective sleep quality and cardiac vagal activity. J. Clin. Med. Res. 8:193. doi: $10.3390 / \mathrm{jcm} 8020193$

Lackey, A. E., Moshiri, M., Pandey, T., Lall, C., Lalwani, N., and Bhargava, P. (2014). Productivity, part 1: getting things done, using e-mail, scanners, reference managers, note-taking applications, and text expanders. J. Am. Coll. Radiol. 11, 481-489. doi: 10.1016/j.jacr.2013.11.020

Lally, P., and Gardner, B. (2013). Promoting habit formation. Health Psychol. Rev. 7, S137-S158. doi: 10.1080/17437199.2011.603640

Lampit, A., Hallock, H., and Valenzuela, M. (2014). Computerized cognitive training in cognitively healthy older adults: a systematic review and meta-analysis of effect modifiers. PLoS Med. 11:e1001756. doi: 10.1371/journal.pmed.1001756

Lee, J., and Stone, A. J. (2020). Combined aerobic and resistance training for cardiorespiratory fitness, muscle strength, and walking capacity after stroke: a systematic review and meta-analysis. J. Stroke Cerebrovasc. Dis. 29:104498. doi: 10.1016/j.jstrokecerebrovasdis.2019.104498

Lee, J. E., Ju, Y. J., Park, E.-C., and Lee, S. Y. (2020). Effect of poor sleep quality on subjective cognitive decline (SCD) or SCD-related functional difficulties: results from 220,000 nationwide general populations without dementia. J. Affect. Dis. 260, 32-37. doi: 10.1016/j.jad.2019.08.082

Lewis, C., Restauri, N., and Clark, T. (2019). Strategies for increasing radiologist efficiency. Curr. Probl. Diagn. Radiol. 48, 103-104. doi: 10.1067/j.cpradiol.2018.12.001

Longo, U. G., Sofi, F., Dinu, M., Berton, A., Cipriani, G., Massaroni, C., et al. (2019). Alpine junior world ski championship: nutritional habits and performance in elite skiers. J. Sports Med. Phys. Fitness 59, 1339-1345. doi: 10.23736/S0022-4707.19.09386-1

Lopez, P. D., Cativo, E. H., Atlas, S. A., and Rosendorff, C. (2019). The effect of vegan diets on blood pressure in adults: a metaanalysis of randomized controlled trials. Am. J. Med. 132, 875-883.e7. doi: 10.1016/j.amjmed.2019.01.044

Lundqvist, C. (2011). Well-being in competitive sports-the feel-good factor? A review of conceptual considerations of well-being. Int. Rev. Sport Exerc. Psychol. 4, 109-127. doi: 10.1080/1750984X.2011.584067

Macnamara, B. N., Moreau, D., and Hambrick, D. Z. (2016). The relationship between deliberate practice and performance in sports: a meta-analysis. Perspect. Psychol. Sci. 11, 333-350. doi: 10.1177/1745691616635591
Malloy-Diniz, L. F., Brevers, D., and Turel, O. (2019). Editorial: etiology, pathogenesis, and consequences of maladaptive habits. Front. Psychol. 10:2613. doi: $10.3389 /$ fpsyg. 2019.02613

Manzoni, G. M., Pagnini, F., Castelnuovo, G., and Molinari, E. (2008). Relaxation training for anxiety: a ten-years systematic review with meta-analysis. $B M C$ Psychiatry 8:41. doi: 10.1186/1471-244X-8-41

Marcora, S. (2016). Can doping be a good thing? Using psychoactive drugs to facilitate physical activity behaviour. Sports Med. 46, 1-5. doi: 10.1007/s40279-015-0412-x

Martland, R., Mondelli, V., Gaughran, F., and Stubbs, B. (2020). Can high-intensity interval training improve physical and mental health outcomes? A metareview of 33 systematic reviews across the lifespan. J. Sports Sci. 38, 430-469. doi: 10.1080/02640414.2019.1706829

McGarry, T. (2013). Routledge Handbook of Sports Performance Analysis. London: Routledge. doi: 10.4324/9780203806913

Melby-Lervåg, M., and Hulme, C. (2013). Is working memory training effective? A meta-analytic review. Dev. Psychol. 49, 270-291. doi: 10.1037/a0028228

Miake-Lye, I. M., Hempel, S., Shanman, R., and Shekelle, P. G. (2016). What is an evidence map? A systematic review of published evidence maps and their definitions, methods, and products. Syst. Rev. 5:28. doi: 10.1186/s13643-016-0204-x

Parker, C. P., Baltes, B. B., Young, S. A., Huff, J. W., Altmann, R. A., LaCost, H. A., et al. (2003). Relationships between psychological climate perceptions and work outcomes: a meta-analytic review. J. Organ. Behav. 24, 389-416. doi: $10.1002 /$ job. 198

Perryman, C. L. (2016). Mapping studies. J. Med. Libr. Assoc. 104, 79-82. doi: 10.3163/1536-5050.104.1.014

Phillips, L. A. (2020). Challenging assumptions about habit: a response to Hagger (2019). Psychol. Sport Exerc. 47:101502. doi: 10.1016/j.psychsport.2019.03.005

Pilcher, J. J., and Huffcutt, A. I. (1996). Effects of sleep deprivation on performance: a meta-analysis. Sleep 19, 318-326. doi: 10.1093/sleep/19.4.318

Raab, M., Lobinger, B., Hoffmann, S., Pizzera, A., and Laborde, S. (2015). Performance Psychology: Perception, Action, Cognition, and Emotion. Amsterdam: Academic Press.

Rampersaud, G. C., Pereira, M. A., Girard, B. L., Adams, J., and Metzl, J. D. (2005). Breakfast habits, nutritional status, body weight, and academic performance in children and adolescents. J. Am. Diet. Assoc. 105, 743-760; quiz 761-742. doi: 10.1016/j.jada.2005.02.007

Rayner, K., Schotter, E. R., Masson, M. E. J., Potter, M. C., and Treiman, R. (2016), So much to read, so little time: how do we read, and can speed reading help? Psychol. Sci. Public Interest. 17, 4-34. doi: 10.1177/1529100615623267

Rebar, A. L., Reynolds, A. C., Ferguson, S. A., and Gardner, B. (2020). Accounting for automatic processes in sleep health. J. Sleep Res. e12987. doi: $10.1111 /$ jsr.12987

Ritter, S. M., and Ferguson, S. (2017). Happy creativity: listening to happy music facilitates divergent thinking. PLoS ONE 12:e0182210. doi: 10.1371/journal.pone. 0182210

Ryan, R. M., and Deci, E. L. (2001). On happiness and human potentials: a review of research on hedonic and eudaimonic well-being. Annu. Rev. Psychol. 52, 141-166. doi: 10.1146/annurev.psych.52.1.141

Ryff, C. D. (2014). Psychological well-being revisited: advances in the science and practice of eudaimonia. Psychother. Psychosom. 83, 10-28. doi: $10.1159 / 000353263$

Ryff, C. D., and Singer, B. (1996). Psychological well-being: meaning, measurement, and implications for psychotherapy research. Psychother. Psychosom. 65, 14-23. doi: 10.1159/000289026

Salas, E., and Cannon-Bowers, J. A. (2001). The science of training: a decade of progress. Annu. Rev. Psychol. 52, 471-499. doi: 10.1146/annurev.psych.52.1.471

Sales, N. M., Pelegrini, P. B., and Goersch, M. C. (2014). Nutrigenomics: definitions and advances of this new science. J. Nutr. Metab. 2014:202759. doi: $10.1155 / 2014 / 202759$

Scionti, N., Cavallero, M., Zogmaister, C., and Marzocchi, G. M. (2019). Is cognitive training effective for improving executive functions in preschoolers? A systematic review and meta-analysis. Front. Psychol. 10:2812. doi: 10.3389/fpsyg.2019.02812

Scott, G., Leritz, L. E., and Mumford, M. D. (2004). The effectiveness of creativity training: a quantitative review. Creat. Res. J. 16, 361-388. doi: 10.1207/s15326934cri1604_1 
Scullin, M. K., Krueger, M. L., Ballard, H. K., Pruett, N., and Bliwise, D. L. (2018). The effects of bedtime writing on difficulty falling asleep: a polysomnographic study comparing to-do lists and completed activity lists. J. Exp. Psychol. Gen. 147, 139-146. doi: 10.1037/xge0000374

Shin, J. C., Kim, J., and Grigsby-Toussaint, D. (2017). Mobile phone interventions for sleep disorders and sleep quality: systematic review. JMIR Mhealth Uhealth 5:e131. doi: 10.2196/mhealth.7244

Simons, D. J., Boot, W. R., Charness, N., Gathercole, S. E., Chabris, C. F., Hambrick, D. Z., et al. (2016). Do "brain-training" programs work? Psychol. Sci. Public Interest. 17, 103-186. doi: 10.1177/1529100616661983

Smith, P. J., Blumenthal, J. A., Hoffman, B. M., Cooper, H., Strauman, T. A., Welsh-Bohmer, K., et al. (2010). Aerobic exercise and neurocognitive performance: a meta-analytic review of randomized controlled trials. Psychos. Med. 72, 239-252. doi: 10.1097/PSY.0b013e3181 d14633

Soltani, S., Jayedi, A., Shab-Bidar, S., Becerra-Tomás, N., and Salas-Salvadó, J. (2019). Adherence to the mediterranean diet in relation to allcause mortality: a systematic review and dose-response meta-analysis of prospective cohort studies. Adv. Nutr. 10, 1029-1039. doi: 10.1093/advances/ nmz041

Stojanovic, M., Grund, A., and Fries, S. (2020). App-based habit building reduces motivational impairments during studying - an event sampling study. Front. Psychol. 11:167. doi: 10.3389/fpsyg.2020.00167

Taetzsch, A., Das, S. K., Brown, C., Krauss, A., Silver, R. E., and Roberts, S. B. (2018). Are gluten-free diets more nutritious? An evaluation of self-selected and recommended gluten-free and gluten-containing dietary patterns. Nutrients 10:1881. doi: 10.3390/nu10121881

Tang, Y. Y. (2014). Short-term meditation intervention improves selfregulation and academic performance. J. Child Adolesc. Behav. 2:154. doi: 10.4172/2375-4494.1000154

Valgeirsdottir, D., and Onarheim, B. (2017). Studying creativity training programs: a methodological analysis. Creat. Innov. Manag. 26, 430-439. doi: $10.1111 /$ caim. 12245

Van De Walle, G. P., and Vukovich, M. D. (2018). The effect of nitrate supplementation on exercise tolerance and performance: a systematic review and meta-analysis. J. Strength Cond. Res. 32, 1796-1808. doi: $10.1519 /$ JSC. 0000000000002046

Viguiliouk, E., Kendall, C. W., Kahleová, H., Rahelić, D., Salas-Salvadó, J., Choo, V. L., et al. (2019). Effect of vegetarian dietary patterns on cardiometabolic risk factors in diabetes: a systematic review and meta-analysis of randomized controlled trials. Clin. Nutr. 38, 1133-1145. doi: 10.1016/j.clnu.2018.05.032

Wen, D., Utesch, T., Wu, J., Robertson, S., Liu, J., Hu, G., et al. (2019). Effects of different protocols of high intensity interval training for VOmax improvements in adults: a meta-analysis of randomised controlled trials. J. Sci. Med. Sport 22, 941-947. doi: 10.1016/j.jsams.2019.01.013

Wilke, J., Müller, A.-L., Giesche, F., Power, G., Ahmedi, H., and Behm, D. G. (2020). Acute effects of foam rolling on range of motion in healthy adults: a systematic review with multilevel meta-analysis. Sports Med. 50, 387-402. doi: 10.1007/s40279-019-01205-7

Wilson-Barnes, S. L., Hunt, J. E. A., Lanham-New, S. A., and Manders, R. J. F. (2020). Effects of vitamin D on health outcomes and sporting performance: implications for elite and recreational athletes. Nutr. Bull. 45, 11-24. doi: 10.1111/nbu.12413

Wood, A. M., Froh, J. J., and Geraghty, A. W. A. (2010). Gratitude and wellbeing: a review and theoretical integration. Clin. Psychol. Rev. 30, 890-905. doi: 10.1016/j.cpr.2010.03.005

Wood, W. (2017). Habit in personality and social psychology. Pers. Soc. Psychol. Rev. 21, 389-403. doi: 10.1177/1088868317720362

Yang, J. (2015). The influence of motor expertise on the brain activity of motor task performance: a meta-analysis of functional magnetic resonance imaging studies. Cogn. Affect. Behav. Neurosci. 15, 381-394. doi: 10.3758/s13415-014-0329-0

Zaccaro, A., Piarulli, A., Laurino, M., Garbella, E., Menicucci, D., Neri, B., et al. (2018). How breath-control can change your life: a systematic review on psycho-physiological correlates of slow breathing. Front. Hum. Neurosci. 12:353. doi: 10.3389/fnhum.2018.00353

Conflict of Interest: The authors declare that the research was conducted in the absence of any commercial or financial relationships that could be construed as a potential conflict of interest.

Copyright (C) 2020 Laborde, Kauschke, Hosang, Javelle and Mosley. This is an openaccess article distributed under the terms of the Creative Commons Attribution License (CC BY). The use, distribution or reproduction in other forums is permitted, provided the original author(s) and the copyright owner(s) are credited and that the original publication in this journal is cited, in accordance with accepted academic practice. No use, distribution or reproduction is permitted which does not comply with these terms. 